\title{
Uncovering undetected hypoglycemic events
}

This article was published in the following Dove Press journal:

Diabetes, Metabolic Syndrome and Obesity:Targets and Therapy

7 March 2012

Number of times this article has been viewed

Jeff Unger

Catalina Research Institute, Chino, CA, USA
Correspondence: Jeff Unger Catalina Research Institute, I4726 Ramona Avenue, Suite II0, Chino, CA 91710 , USA

Tel + I 9095908409

Fax +19098995013

Email jungermd@aol.com
Abstract: Hypoglycemia is the rate-limiting factor that often prevents patients with diabetes from safely and effectively achieving their glycemic goals. Recent studies have reported that severe hypoglycemia is associated with a significant increase in the adjusted risks of major macrovascular events, major microvascular events, and mortality. Minor hypoglycemic episodes can also have serious implications for patient health, psychological well being, and adherence to treatment regimens. Hypoglycemic events can impact the health economics of the patient, their employer, and third-party payers. Insulin treatment is a key predictor of hypoglycemia, with one large population-based study reporting an overall prevalence of $7.1 \%$ (type 1 diabetes mellitus) and $7.3 \%$ (type 2 diabetes mellitus) in insulin-treated patients, compared with $0.8 \%$ in patients with type 2 diabetes treated with an oral sulfonylurea. Patients with type 1 diabetes typically experience symptomatic hypoglycemia on average twice weekly and severe hypoglycemia once annually. The progressive loss of islet cell function in patients with type 2 diabetes results in a higher risk of both symptomatic and unrecognized hypoglycemia over time. Patients with diabetes who become hypoglycemic are also more susceptible to developing defective counter-regulation, also known as hypoglycemia awareness autonomic failure, which is life-threatening and must be aggressively addressed. In patients unable to recognize hypoglycemia symptoms, frequent home monitoring or use of continuous glucose sensors are critical. Primary care physicians play a key role in the prevention and management of hypoglycemia in patients with diabetes, particularly in those requiring intensive insulin therapy, yet physicians are often unaware of the multitude of consequences of hypoglycemia or how to deal with them. Careful monitoring, adherence to guidelines, and use of optimal treatment combinations are all important steps toward improving care in patients with diabetes. The most important goals are for primary care physicians to recognize that every patient treated with antihyperglycemic medications is at risk of iatrogenic hypoglycemia and to ask patients about hypoglycemia at every visit.

Keywords: hypoglycemia, insulin analogs, type 1 diabetes mellitus, type 2 diabetes mellitus

\section{Increasing awareness of hypoglycemia}

Achieving optimal glycemic control is a priority for the management of diabetes in order to minimize the risk of long-term complications. However, iatrogenic (therapyinduced) hypoglycemia is a common side effect of antihyperglycemic therapies. In fact, hypoglycemia is a key limiting factor in the successful glycemic management of many diabetes patients, with recent studies indicating a substantial prevalence of hypoglycemic events, not only in patients with type 1 diabetes mellitus, but also in patients with type 2 diabetes mellitus, particularly in those who require intensive insulin therapy and frequent blood glucose monitoring to achieve optimal glycemic control. ${ }^{1,2}$ 
The detrimental impact of hypoglycemia is highlighted in a number of recently published studies, which have mainly focused on the effects of severe hypoglycemic events. In the past, the demonstration of a direct relationship between hypoglycemia and mortality has been controversial. However, new studies have reported that severe hypoglycemia is associated with a significant increase in the adjusted risks of major macrovascular events (hazards ratio [HR] 2.88), major microvascular events (HR 1.81), and mortality (HR 2.69), as shown in Figure 1. ${ }^{3}$ The mortality rate among patients with severe hypoglycemia was $19.5 \%$, compared with $9 \%$ among those who did not report severe hypoglycemia. ${ }^{3}$ Recent and ongoing studies in both the US and Europe also point to the substantial economic costs associated with hypoglycemia, which suggest that hypoglycemic events have a wide-ranging economic impact on the health care system, the patient, and the patient's family, friends, and caregivers, as well as an estimated total annual cost per episode of up to $\$ 1500$. Finally, failure to recognize and treat severe hypoglycemia can result in devastating immediate neurological consequences, such as altered consciousness, seizures, and coma.

While severe hypoglycemic events are undoubtedly dangerous to patients, equally important are nonsevere hypoglycemic events, which are frequently and incorrectly dismissed as unimportant because they can be asymptomatic. In fact, nonsevere hypoglycemic events are actually much more common than severe hypoglycemic events, yet, because symptoms of hypoglycemia are nonspecific, even symptomatic, nonsevere hypoglycemic episodes may go unrecognized. Even if they are recognized, they may not be significant enough to be remembered by the patient and to be mentioned to the primary care physician and are therefore also significantly under-reported. ${ }^{4}$ Recurrent episodes of untreated hypoglycemia can lead to hypoglycemia-associated autonomic failure ${ }^{5-7}$ (Figure 2), an impaired ability of the body to counter-regulate subsequent and more serious events, which leads to unawareness of hypoglycemia. The blood glucose level at which the body normally initiates a response is lowered, and serious clinical effects may occur before symptomatic awareness of hypoglycemia. Hypoglycemia also commonly goes undetected when it occurs during the night. Nocturnal hypoglycemia can lead to serious clinical consequences, including sudden death during sleep, thought to be a result of cardiac rate and rhythm disturbances in response to prolonged nocturnal hypoglycemia..$^{4-7}$

There are multiple definitions of hypoglycemia and conflicting data on the incidence of hypoglycemia available in the scientific literature. Combined with the fact that hypoglycemic events often go undetected for a number of different reasons, this ultimately means that primary care physicians on the front line of diabetes care, who are responsible for guiding therapy to achieve euglycemic control in patients with diabetes, may not be aware of the significant impact of hypoglycemia.

The purpose of this review is to discuss the importance of all hypoglycemic events in the successful management of patients with diabetes, with the aim of improving understanding of the impact and consequences of hypoglycemia, emphasizing new data regarding the incidence of hypoglycemia in type 1 and type 2 diabetes patients taking insulin, exploring new methods to aid the diagnosis and treatment of hypoglycemia, and

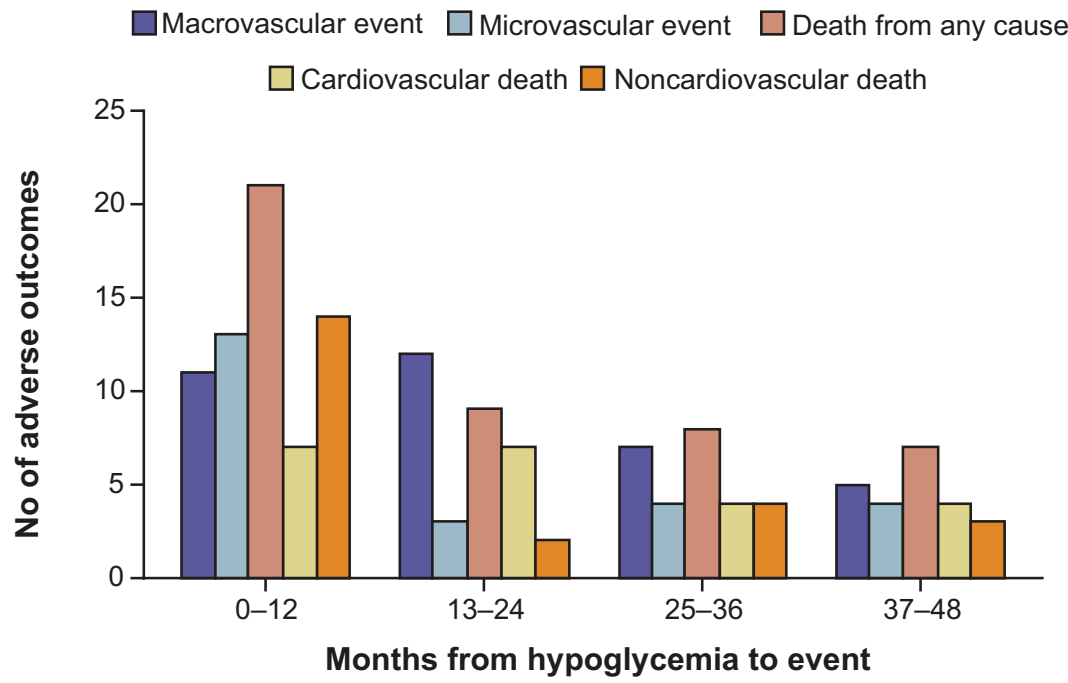

Figure I Frequency of adverse clinical outcomes after the occurrence of severe hypoglycemia event.

Copyright @ 2010, Massachusetts Medical Society. Reprinted with permission from Zoungas S, Patel A, Chalmers J, et al. Severe hypoglycemia and risks of vascular events and death. N Engl J Med. 2010;363(I5):|4|0-14|8. 


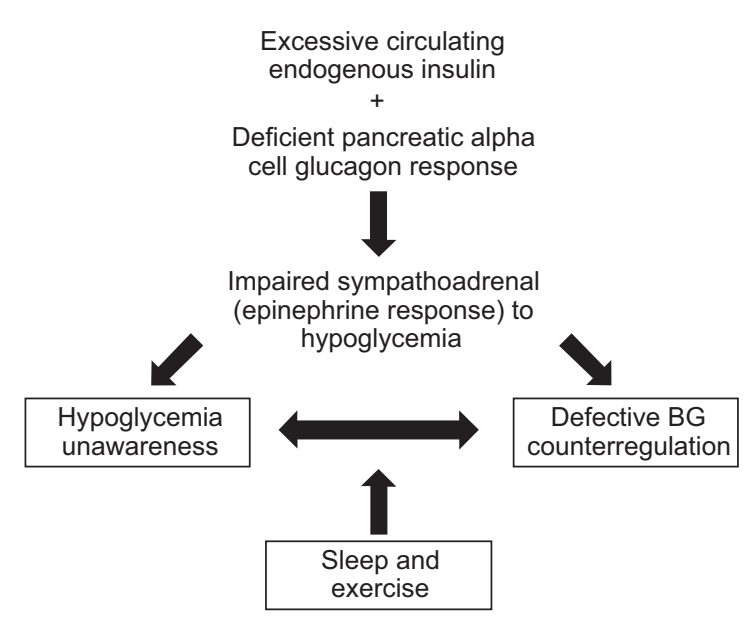

Figure 2 Diagrammatic representation of the concept of hypoglycemia-associated autonomic failure.

Copyright (c) 201I, Vendome Group. Reprinted with permission from Unger J, Parkin C. Hypoglycemia in insulin-treated diabetes: a case for increased vigilance. Postgrad Med. 201 I; I23(4):8I-9I.

Abbreviation: BG, blood glucose.

highlighting the need for newer therapeutic agents with a lower risk of causing hypoglycemia.

\section{Epidemiology of hypoglycemia Definitions}

Hypoglycemia occurs when blood glucose concentrations fall below the level necessary to maintain the body's requirement for energy and stability in a proper manner. ${ }^{6}$ Currently, there is no consensus or standardized definition of hypoglycemia. A number of different scientific organizations offer different definitions and often there are substantial differences in interpreting and reporting hypoglycemic events among investigators participating in clinical trials with different pharmaceutical companies, and this can lead to a great deal of confusion as to what constitutes a hypoglycemic event.

Among the earliest clinical definitions of hypoglycemia was the presence of Whipple's triad, incorporating observations of decreased blood glucose concentrations, symptoms compatible with hypoglycemia, and rapid attenuation of those symptoms upon correction of blood glucose, a definition that remains clinically relevant today. Other definitions have been provided by professional medical organizations that include the American Diabetes Association (ADA) and the American Association of Clinical Endocrinologists (AACE) in an attempt to define the clinical severity of hypoglycemia, classify events according to the presence or absence of a blood glucose test, and identify a universal threshold level for blood glucose at which hypoglycemia is diagnosed. Each organization differs in their set thresholds, which range from $<3.9 \mathrm{mmol} / \mathrm{L}(<70 \mathrm{mg} / \mathrm{dL})$ down to $<3 \mathrm{mmol} / \mathrm{L}$
$(<54 \mathrm{mg} / \mathrm{dL}){ }^{4,8-10}$ The US Food and Drug Administration (FDA) recommends following the guidelines set by the ADA in order to achieve some level of consistency. ${ }^{11}$

The ADA Workgroup on Hypoglycemia has defined hypoglycemia as "all episodes of abnormally low blood glucose concentration that expose the individual to potential harm", 9 and both this workgroup and the current ADA guidelines (2012) define hypoglycemia as a fasting blood glucose of $<3.9 \mathrm{mmol} / \mathrm{L}(<70 \mathrm{mg} / \mathrm{dL}){ }^{9}{ }^{910}$ This threshold is higher than most values commonly used in clinical trials, because the aim of these guidelines is not to estimate the prevalence of hypoglycemia, but to try to prevent it from happening. The ADA suggests that this threshold level will allow the patient time to take action to prevent hypoglycemia and allows for a margin of error with blood glucose self-monitoring devices. The guidelines also divide the definitions of hypoglycemia into asymptomatic (hypoglycemia not accompanied by typical symptoms) and symptomatic (hypoglycemia accompanied by typical symptoms), and provide a detailed definition of severe hypoglycemia as an episode in which the patient is unable to self-treat and requires external intervention and assistance and as an episode which may be accompanied by neurological effects sufficient to induce seizure or coma.

Patient perceptions of hypoglycemia can differ substantially from clinical definitions, affecting the true number of events that are reported to primary care physicians. A patient who experiences hypoglycemia for the first time will often refer to that event as being "severe" because of fears that they have become powerless to prevent their own morbidity without outside assistance. ${ }^{8}$ Primary care physicians must understand that hypoglycemic events are potentially life-altering. Therefore, patients and their families must be educated to minimize the frequency of the events as well as recognize, predict, and appropriately manage acute hypoglycemia.

\section{Prevalence}

Many clinical reviews have attempted to determine the exact prevalence of hypoglycemia among patients with diabetes. Clinicians may underestimate the frequency of hypoglycemia in their patient population with type 2 diabetes. ${ }^{12}$ In advanced type 2 diabetes, disease progression and loss of $\beta$-cell function parallel a loss in hormonal counter-regulation leading to hypoglycemia. ${ }^{5}$ Thus, patients with advanced type 2 diabetes who are candidates for therapeutic intensification with insulin therapy will have a higher risk of developing hypoglycemia than those who are at an earlier stage of the disease. ${ }^{5,12}$

Studies have shown that the prevalence of hypoglycemia in patients with advanced type 2 diabetes who require insulin 
treatment may be the same as that in patients with type 1 diabetes. The Diabetes Audit and Research in Tayside, Scotland (DARTS) study of 367,501 people, 8655 of whom had diabetes, identified a total of 244 episodes of severe hypoglycemia in 160 patients. The overall prevalence was $7.1 \%$ in patients with type 1 diabetes and $7.3 \%$ in patients with type 2 diabetes treated with insulin, compared with $0.8 \%$ in patients with type 2 diabetes treated with an oral sulfonylurea (Table 1). ${ }^{12}$ A subsequent DARTS study compared a selected cohort of type 1 diabetes and insulin-treated type 2 diabetes patients and confirmed that the incidence of severe hypoglycemia in patients was higher than previously reported, and that insulin treatment was a key predictor of hypoglycemia in this population. ${ }^{13}$ A multicenter study of 11,140 patients with type 2 diabetes from across 20 different countries found that during a median follow-up period of 5 years, $2.1 \%$ of patients experienced a severe hypoglycemic event. When assessed according to treatment group, $2.7 \%$ of those who received intensive blood glucose control experienced a severe hypoglycemic event, compared with only $1.5 \%$ of the standard blood glucose control group. ${ }^{3}$ The annual hypoglycemic rates according to treatment can be seen in Table $2 .^{3}$

Research also suggests that the incidence of hypoglycemia is particularly high among patients treated with insulin over extended periods of time, again reinforcing the idea that advanced disease progression and increased insulin use subsequently increases the risk of hypoglycemia. The UK Study Group found that the incidence of severe hypoglycemia in patients with type 1 diabetes treated with insulin for $>15$ years was three times higher than in those treated for $<5$ years. In patients with type 2 diabetes, the prevalence of severe hypoglycemia increased from $7 \%$ to $25 \%$ when comparing patients treated with insulin for $<2$ years with those treated for $>5$ years, respectively. ${ }^{14}$

Mild symptomatic and asymptomatic hypoglycemia are even more common than severe hypoglycemia, accounting for

Table I Incidence of severe hypoglycemia requiring NHS resources

\begin{tabular}{lll}
\hline Type of diabetes & Treatment modality & Incidence \\
\hline Type I & Insulin & II.5 $(9.4-13.6)$ \\
Type 2 & Insulin & II.8 $(9.5-14.1)$ \\
Type 2 & SU tablets & $0.9(0.6-1.3)$ \\
Type 2 & Metformin or diet & $0.05(0.0 \mathrm{I}-0.2)$ \\
\hline
\end{tabular}

Note: Data are events expressed per 100 patient-years $(95 \% \mathrm{Cl})$.

Copyright @ 2003, American Diabetes Association. Reprinted with permission from Leese GP, Wang J, Broomhall J, et al. Frequency of severe hypoglycemia requiring emergency treatment in type I and type 2 diabetes: a population-based study of health service resource use. Diabetes Care. 2003;26(4): I I 76-I I 80.

Abbreviations: $\mathrm{Cl}$, confidence interval; NHS, Ninewells Hospital and Medical School (United Kingdom); SU, sulfonylurea. up to $88 \%$ of all hypoglycemic events. ${ }^{15}$ Indeed, it has been estimated that blood glucose levels may be $<2.7-3.3 \mathrm{mmol} / \mathrm{L}$ $(<50-60 \mathrm{mg} / \mathrm{dL})$ up to $10 \%$ of the time. ${ }^{5}$ Retrospective estimates of the incidence of mild, symptomatic hypoglycemia have varied from 29 to 162 episodes per patient per year. ${ }^{13,14,16}$ Data from a number of other studies suggest that nonsevere hypoglycemic events occur in $24 \%-60 \%$ of patients with diabetes. ${ }^{15}$ This variability likely reflects the difficulty in recalling events with any accuracy beyond one week. Prospective studies have indicated that the majority of insulin-treated patients experience an average of two symptomatic episodes per week. ${ }^{5}$ The UK Hypoglycaemia Study Group also reported a concurrent increase in mild hypoglycemic events, from 0.1 events/patient per year to 0.7 events/patient per year, in patients treated with insulin for $>5$ years compared with those treated for $<2$ years. ${ }^{14}$

Though the risk of iatrogenic hypoglycemia is highest among patients treated with insulin, there are risks associated with other treatments. Early in the course of progression of type 2 diabetes, patients may respond to oral antidiabetic drugs, such as metformin or thiazolidinediones, and to sulfonylureas. Sulfonylurea therapy, which increases insulin output from the pancreas, is one of the key contributors to hypoglycemia in patients with type 2 diabetes who are early in the progression of the disease. Hypoglycemic risk is highest with long-acting sulfonylureas, such as chlorpropamide and glibenclamide, while shorter-acting sulfonylureas, such as glipizide, are associated with a much lower risk. Prandial blood glucose regulators, such as repaglinide and nateglinide, also have a low hypoglycemic potential. The risk of hypoglycemia with oral antidiabetes drugs is variable and, as with sulfonylureas, depends upon their respective pharmacokinetic and pharmacodynamic profiles. Though the majority of these drugs are associated with a lower risk of hypoglycemia, it is important to remember that if insulin or insulin secretagogues, such as a sulfonylurea, are added into the treatment regimen as the disease progresses, the risk of hypoglycemia will increase. ${ }^{17}$

The incidence of type 2 diabetes is projected to increase in coming years, while the average age of patients with type 2 diabetes is decreasing; therefore, the number of patients with advanced type 2 diabetes, for whom sulfonylureas and oral antidiabetes drugs will not provide sufficient glycemic control, and who will require the addition of insulin to their treatment regimen, is also likely to increase dramatically. Combined with increasingly tighter glycemic targets, this may contribute to an increasing prevalence of hypoglycemia in the future. 
Table 2 Episodes of severe and minor hypoglycemia in all study participants and according to treatment group

\begin{tabular}{|c|c|c|c|c|}
\hline Variable & $\begin{array}{l}\text { All participants } \\
(n=I I, \mid 40)\end{array}$ & $\begin{array}{l}\text { Intensive } \\
\text { blood glucose } \\
\text { control } \\
(n=557 \text { I })\end{array}$ & $\begin{array}{l}\text { Standard } \\
\text { blood glucose } \\
\text { control } \\
(n=5569)\end{array}$ & $\begin{array}{l}\text { Hazards ratio } \\
(95 \% \mathrm{Cl})\end{array}$ \\
\hline Severe hypoglycemia & & & & $1.86(1.40-2.40)$ \\
\hline \multicolumn{5}{|l|}{ Patients (n, \%) } \\
\hline Episodes (n) & $23 I(2.1)$ & $150(2.7)$ & $81(1.5)$ & \\
\hline 1 & 184 & 120 & 64 & \\
\hline 2 & 35 & 22 & 13 & \\
\hline$\geq 3$ & 12 & 8 & 4 & \\
\hline Rate (person/year) & 0.006 & 0.007 & 0.004 & \\
\hline Minor hypoglycemia & & & & $1.58(1.49-1.68)$ \\
\hline \multicolumn{5}{|l|}{ Patients (n, \%) } \\
\hline Episodes (n) & $4975(44.7)$ & $2898(52.0)$ & $2077(37.3)$ & \\
\hline 1 & 2610 & 1529 & 1081 & \\
\hline 2 & 671 & 397 & 274 & \\
\hline$\geq 3$ & 1694 & 972 & 722 & \\
\hline Rate (person/year) & 1.1 & 1.2 & 0.9 & \\
\hline
\end{tabular}

Copyright $\odot$ 2010, Massachusetts Medical Society. Reprinted with permission from Zoungas S, Patel A, Chalmers J, et al. Severe hypoglycemia and risks of vascular events and death. N Engl J Med. 2010;363(15):1410-14|8.

Abbreviations: $\mathrm{BG}$, blood glucose; $\mathrm{Cl}$, confidence interval.

\section{Consequences of hypoglycemia}

Hypoglycemia is both a psychological and pathophysiological barrier to optimal glycemic control in patients with diabetes. The associated physical morbidity ranges from unpleasant symptoms, such as anxiety, palpitations, tremors, sweating, hunger, and paresthesia, to more serious neurological sequelae, including behavioral changes, cognitive dysfunction, seizures, coma, and death. ${ }^{5}$

\section{Neurological impairment}

The brain relies on blood glucose for fuel, so hypoglycemia is, not surprisingly, linked to neurological defects. Two main areas of brain function are reported to be affected, ie, cognitive ability, most typically the hippocampal function such as memory, and affective ability, affecting mood and levels of anxiety. ${ }^{5,18}$ Typically, blood glucose levels of $<1 \mathrm{mmol} / \mathrm{L}$ $(18 \mathrm{mg} / \mathrm{dL})$, termed neuroglycopenia, result in coma, loss of consciousness, and death. Even in cases where neuroglycopenia is not fatal, severe neurological impairments can lead to permanent brain damage. Fortunately, severe neurological defects are relatively rare, even in patients who experience recurrent hypoglycemia. However, less profound hypoglycemia, for example, where blood glucose levels are $<2 \mathrm{mmol} / \mathrm{L}$ (36 $\mathrm{mg} / \mathrm{dL})$, can still interfere with the patient's ability to perform everyday tasks, leading to cognitive deterioration, irritability, belligerent behaviors, drowsiness, blurred vision, difficulties in speaking and communicating, confusion, and faintness. ${ }^{6}$ These effects can make performance of certain tasks, such as driving, much more dangerous. ${ }^{19}$ Hypoglycemia-induced neurological impairment can be particularly dangerous in the elderly and can lead to accelerated onset of dementia. One study quantified the risk of dementia attributable to hypoglycemia as $2.39 \%$ per year. ${ }^{20}$ However, the precise effects of hypoglycemia on cognitive abilities remain somewhat controversial. A range of studies show different outcomes from impairment to enhancement to no change. It has been suggested that recurrent hypoglycemia may not affect cognitive function during periods of euglycemia, but could significantly impact future performance at times of hypoglycemia instead. ${ }^{18}$ Because recurrent hypoglycemia lowers the blood glucose concentration at which symptomatic and hormonal responses are initiated, cognitive impairment and subclinical brain damage may occur prior to the onset of visible symptoms of hypoglycemia.

\section{Cardiovascular outcomes}

As with neurological consequences, there is controversy over the effects of hypoglycemia on cardiovascular outcomes. There have been multiple anecdotal reports and observational studies suggesting that hypoglycemia may increase the risk of acute coronary syndromes and increase the risk of death in patients hospitalized for myocardial infarction. A number of trials, in particular the Action to Control Cardiovascular Risk in Diabetes (ACCORD) trials, investigating the effects of intensive blood glucose control on macrovascular outcomes in patients with type 2 diabetes, have demonstrated increased mortality rates in patients who experienced hypoglycemia. ${ }^{21,22}$ 
However, a meta-analysis of various trials showed that intensive blood glucose control reduced the risk of myocardial infarction by $15 \%$, with no adverse effect on the risk of death, although the risk of severe hypoglycemia was increased. ${ }^{23}$ Furthermore, post hoc analyses suggest the increased mortality rates observed in the ACCORD study may not be directly explained by high rates of hypoglycemia. ${ }^{24}$ The exact reason for the observed increase in mortality rates remains unclear. It was not attributed to any particular drug used in the study, although many different drug regimens and combinations were used in ACCORD to achieve tight glycemic control. Thus, attributing the increased risk to any one drug is extremely difficult.

\section{Hypoglycemia unawareness}

Repeated hypoglycemic events can lead to hypoglycemia unawareness, whereby hormonal, autonomic, sympathetic neural, and adrenomedullary responses are attenuated, such that the warning symptoms of developing hypoglycemia are essentially lost. This subsequently compromises natural behavioral defenses against hypoglycemia, such as the ingestion of food, so that instead of an episode of mild hypoglycemia developing that can be easily self-managed by the patient, more serious episodes of hypoglycemia may occur that require external intervention. Indeed, studies have shown that adults with type 1 diabetes who have impaired awareness of hypoglycemia are much more likely to be exposed to asymptomatic hypoglycemia and are at higher risk of developing severe hypoglycemia than those with normal awareness. A 4-week study that measured capillary blood glucose four times daily demonstrated that patients with hypoglycemia unawareness exhibit twice the frequency of all types of hypoglycemia ( 7.9 versus 3.7 in those with normal awareness), with seven times the incidence of asymptomatic hypoglycemic events (3.7 versus 0.5$)$ and an annual prevalence of severe hypoglycemia of 53\% versus just $5 \%$ in those with normal awareness. ${ }^{25}$

Hypoglycemia unawareness occurs as a result of a physiological response to recurrent hypoglycemic events known as hypoglycemia-associated autonomic failure, ${ }^{5-7}$ as described earlier (see Figure 2). ${ }^{7}$ It is proposed that, over time, repeated episodes of mild hypoglycemia cause the normal glycemic thresholds for initiating sympathoadrenal, symptomatic, and cognitive responses to subsequent hypoglycemia to shift towards lower blood glucose concentrations. This impairs the natural defense mechanisms required for prevention and reversal of hypoglycemia. Hypoglycemia-associated autonomic failure creates a vicious circle, because patients with type 1 diabetes already have a defective blood glucose counter-regulatory response. Hypoglycemia unawareness ultimately leads to a significantly reduced detection of hypoglycemia in the clinical setting and to further and more severe episodes of hypoglycemia. ${ }^{5}$ Three independent studies have shown that as little as 2-3 weeks of scrupulous avoidance of hypoglycemia can reverse hypoglycemia unawareness. ${ }^{5}$

\section{Psychological consequences}

The psychological consequences of hypoglycemia include subsequent fear of hypoglycemia, guilt relating to fear of hypoglycemia, failure to comply with therapeutic regimens, high levels of anxiety, and low levels of satisfaction and happiness. Fear of hypoglycemia is a particularly important problem and is becoming almost as much of a barrier to glycemic control as hypoglycemia itself. ${ }^{26}$ The Hypoglycemia Fear Survey (HFS), first published in 1987, and its updated counterpart HFS-II, are used to measure behaviors (HFS-B) and worries (HFS-W) related to hypoglycemia in adults with type 1 diabetes. They describe behaviors that patients may engage in to avoid hypoglycemia, such as maintaining higher blood glucose levels than recommended, avoiding being alone, and limiting exercise or physical activity, or concerns they may have about hypoglycemic episodes, such as nocturnal episodes. HFS-B and HFS-W scores have been shown to be significantly higher in women than in men and among patients who have experienced severe hypoglycemia in the past compared with those that have not. ${ }^{27}$

Fear of hypoglycemia is not just a problem for patients with diabetes, but also for the primary care physicians who treat them. The evidence suggests that if patients experience repeated severe hypoglycemic events, both the patient's and the physician's subsequent treatment policy are affected. One study reviewed hospital records and examined daily insulin doses and glycated hemoglobin $\left(\mathrm{HbA}_{1 \mathrm{c}}\right)$ levels $0-3$ months before and 2-6, 7-11, and 12-16 months after an episode of severe hypoglycemia (coma and/or convulsion) in patients with insulin-dependent diabetes. Forty-three patients experienced a total of 48 episodes of severe hypoglycemia, with five patients experiencing two events. It was found that, in $69 \%$ of these cases, either the physician or patient or both decreased the daily insulin dose. Furthermore, physicians decreased the insulin dose in 14 of 33 patients in whom the cause of hypoglycemia was preventable and due to a cause other than erroneous administration of excess insulin. ${ }^{28}$

\section{Economic costs}

The economic impact of hypoglycemia has been examined in a number of studies in the US and Europe. The economic 
costs range in their impact across the health care system, the patient and family, friends, and unpaid caregivers. Costs to the patient can include loss of work productivity, direct and indirect medical costs, and loss of earnings through extended periods of unemployment. Episodes requiring hospitalization are particularly costly. ${ }^{29,30}$ One study conducted in the UK examined 244 episodes of severe hypoglycemia in 160 patients with type 1 or type 2 diabetes over the course of one year and estimated the total cost of emergency treatment for these events to be approximately $£ 92,078,{ }^{12}$ which equates to an average cost of almost $£ 400$ per episode. Several US studies have estimated the annual total costs per patient attributable to hypoglycemia to be between $\$ 1400$ and \$1500, and have also estimated medical and indirect costs and estimated work days lost per hypoglycemic event (Tables 3 and 4). ${ }^{29}$ However, nonsevere hypoglycemic events also have a substantial economic impact. A retrospective review performed in Canada demonstrated that nonsevere hypoglycemic events accounted for $13 \%$ of all out-of-pocket costs related to diabetes. ${ }^{31}$ Nonsevere hypoglycemic events reportedly occur more frequently on work days, significantly impacting work productivity and generating substantial costs for the employer and the employee. A recent multicountry study assessing the impact of nonsevere hypoglycemic events in a working population determined that lost productivity costs range from $\$ 15.26$ to $\$ 93.47$ per event and account for 8.3-15.9 hours of lost work time. When events occurred during the workday, $18.3 \%$ of respondents missed an average of 9.9 hours of work. When they occurred outside of work, hypoglycemic events led to $23.7 \%$ of respondents arriving late to work or missing a full day. The impact on work productivity was most substantial for episodes of nocturnal hypoglycemia, with up to 14.7 hours of work time lost. ${ }^{15}$ Recently reported data at the ADA 2011 Scientific Sessions suggested that hypoglycemia events identified from health care claims are associated with increased use of short-term disability and absenteeism leave. On average, patients with hypoglycemia were more likely to use these types of leave and had more days of leave than control patients over the course of a 6-month study. ${ }^{32}$

\section{Detecting and uncovering hypoglycemia}

The key to preventing and minimizing the inherent risks and costs associated with hypoglycemia is to improve monitoring and detection, in particular by improving recognition of recurrent episodes of asymptomatic, nonsevere, or nocturnal hypoglycemia in patients at risk and identifying patients with hypoglycemia unawareness. Ultimately, the most important goal is for all primary care physicians to recognize that every patient treated with antihyperglycemic medications is at risk of iatrogenic hypoglycemia, and to ask patients about hypoglycemia at each and every visit. Table 5 lists questions the primary care physician can ask at each visit in order to highlight all hypoglycemic episodes that may have occurred since the last visit. ${ }^{33}$ Information gathered about hypoglycemic events will help primary care physicians to assess patient understanding of hypoglycemia and to understand more about potential causes, severity, and frequency of hypoglycemia. This will allow them to respond appropriately to hypoglycemic events by counseling patients, referring them to educational programs, or adjusting components of the treatment regimen, such as short-term or long-term glycemic goals, type of antidiabetes medication, and frequency or type of blood glucose monitoring. In patients with a history of hypoglycemia unawareness, a 2-3-week period of meticulous avoidance of hypoglycemia should be considered as a first-line response. ${ }^{7}$ It is important to note that, although experts have proposed relaxing glycemic goals in vulnerable individuals such as elderly patients, studies have indicated that relaxing glycemic goals does not necessarily reduce hypoglycemic risk. For example, the American Geriatrics

Table 3 Annual total costs per patient attributable to hypoglycemia

\begin{tabular}{|c|c|c|c|c|c|}
\hline Study & Cost year & Treatment arm & Mean (SD) & Median & Expected cost \\
\hline \multirow[t]{2}{*}{ Cobden $^{75}$} & 2006 & Insulin vial and syringe & $\$ 1528(\$ 2336)$ & $\$ 490$ & \\
\hline & & Biphasic insulin analog pen & $\$ 620(\$ 899)$ & $\$ 142$ & \\
\hline \multirow[t]{2}{*}{ Lee et $\mathrm{al}^{68}$} & 2006 & Insulin vial and syringe & $\$ 1415(\$ 2556)$ & $\$ 533$ & \\
\hline & & Insulin analog pen & $\$ 627(\$ 993)$ & $\$ 172$ & \\
\hline \multirow[t]{2}{*}{ Misurski*,76 } & Data gathered 2006-2008 & Exenatide & & & $\$ 78$ \\
\hline & & Insulin glargine & & & $\$ 196$ \\
\hline
\end{tabular}

Notes: *Estimate derived from model using incidence rates (adjusted for patient characteristics) and estimated per event hypoglycemia costs based on mean and median costs per event pooled for both treatment groups. For ease of comparison in this table, reported cost per 100 patients has been converted to cost per patient.

Copyright (c) 2010, Turner White Communications, Inc. Reprinted with permission from Zhang Y, Wieffer H, Modha R, Balar B, Pollack M, Krishnarajah G. The burden of hypoglycemia in type 2 diabetes: a systematic review of patient and economic perspectives. J Clin Outcomes Manage. 20 I0; I7(I2):547-557.

Abbreviation: SD, standard deviation. 
Table 4 Costs per hyperglycemic episode

\begin{tabular}{|c|c|c|c|}
\hline Event severity & $\begin{array}{l}\text { Estimated medical } \\
\text { cost/event }\end{array}$ & $\begin{array}{l}\text { Estimated work } \\
\text { days lost }\end{array}$ & $\begin{array}{l}\text { Estimated } \\
\text { indirect } \\
\text { cost/event }\end{array}$ \\
\hline $\begin{array}{l}\text { Mild: patient experiences hypoglycemic symptoms requiring assistance } \\
\text { from a second person but no medical attention is needed }\end{array}$ & $€ 26.0$ & 0.22 & 37.0 \\
\hline $\begin{array}{l}\text { Moderate: patient seeks medical attention for hypoglycemia but is not } \\
\text { admitted to hospital overnight }\end{array}$ & $€ 334.7$ & 0.27 & 45.3 \\
\hline Severe: patient is admitted to hospital because of hypoglycemia & $€ 2906.8$ & 6.60 & 1110.6 \\
\hline
\end{tabular}

Society 2003 guidelines ${ }^{34}$ recommend relaxing the glycemic goal to an $\mathrm{HbA}_{1 \mathrm{c}}$ level of $8 \%$ in older patients, yet a recent study by Munshi et al that evaluated patients $\geq 69$ years of age with $\mathrm{HbA}_{1 \mathrm{c}}$ values $\geq 8 \%$ found an unexpectedly high rate of hypoglycemic episodes among this population, suggesting that simply relaxing $\mathrm{HbA}_{1 \mathrm{c}}$ goals may not be adequate to protect older adults against hypoglycemia. ${ }^{35}$ The ADA standards for $2012^{10}$ recommend using the goals set for younger adults in older adults as well, although they also suggest that these goals may be relaxed for patients who are not functional or cognitively intact, or do not have a significant life expectancy. ${ }^{36,37}$

The many definitions of hypoglycemia make it particularly difficult for primary care physicians to know what constitutes a true episode of hypoglycemia. Widespread use of the ADA guidelines as recommended by the FDA could help to standardize recognition and treatment of hypoglycemia. It is also important for physicians to recognize the difficulties of detecting nocturnal and asymptomatic hypoglycemia, both of which contribute to a substantial proportion of hypoglycemic events and can lead to a greater incidence of severe hypoglycemic events because of hypoglycemia unawareness and hypoglycemia-associated autonomic failure and ultimately to serious complications, such as sudden death during sleep. A study using continuous glucose monitoring identified unrecognized hypoglycemia in $60 \%$ of patients; $73.7 \%$ of those episodes occurred during the night, with the highest incidence in children aged under 5 years. ${ }^{\text {? }}$

It is also important for primary care physicians to be aware of when hypoglycemic events are most likely to occur while patients are in their care. In addition to continuously monitoring patients with type 1 diabetes, physicians are likely to be responsible for the initiation and titration of insulin therapy in patients who are no longer meeting glycemic targets. Hypoglycemic events are most likely to occur in these patients during the first 14-16 weeks following initiation of insulin therapy and/or during insulin dose titration. ${ }^{38}$

\section{Blood glucose monitoring}

One way that detection of hypoglycemia can be improved is by careful blood glucose monitoring. This is a core component of effective diabetes self-management in insulin-treated patients. There are two main options for blood glucose monitoring, ie, continuous glucose monitoring and selfmonitoring of blood glucose. The testing regimen depends upon the specific therapeutic regimen that is in use, but generally, frequent self-monitoring of blood glucose will allow sufficient assessment of glycemic patterns over a 24-hour period. Monitoring should not be limited to daytime hours and should include periodic nocturnal surveillance to detect

Table 5 Questions about hypoglycemic events to consider at every patient visit

- When did the event(s) occur? (daytime versus overnight)

- Under what circumstances did they occur? (missed meal, following exercise, excess medication)

- What were the symptoms?

- What was the blood glucose reading?

- How did patient treat the hypoglycemia?

- Did the patient require assistance from another person in order to reverse the hypoglycemia?

- Did the hypoglycemic event reoccur later within a 24-hour period?

- What was done? (eg, carbohydrates ingested, follow-up blood glucose monitoring)

- How soon did hypoglycemia resolve? (blood glucose levels rose to $3.9 \mathrm{mmol} / \mathrm{L}[70 \mathrm{mg} / \mathrm{dL}]$ )

- How fearful is the patient or the family of hypoglycemia?

- Do they test before driving?

- Do patients "stack insulin" (re-bolus rapid insulin analog within 3 hours of a similar injection)?

- At what glycemic level does the patient perceive hypoglycemia? (If $<0.8 \mathrm{mmol} / \mathrm{L}$ [ $<50 \mathrm{mg} / \mathrm{dL}$ ], patient may have hypoglycemiaassociated autonomic failure)

- Some patients prefer being "low" rather than "high" because they fear the consequences of acute or chronic hyperglycemia. Does your patient understand the consequences of hypoglycemia?

Copyright (c) 201I, Dove Medical Press, Ltd. Reprinted with permission from Unger J. Insulin initiation and intensification in patients with type 2 diabetes mellitus for the primary care physician. Diabetes Metab Syndr Obes. 201 1;4:253-26I.

Abbreviation: HAAF, hypoglycemia-associated autonomic failure. 
episodes of nocturnal or early-morning hypoglycemia. In order to uncover asymptomatic hypoglycemia, hypoglycemia unawareness, or high-risk patterns, periodic 7-point profile testing should be used as outlined in the AACE guidelines. $^{7}$

Primary care physicians play a vital role in ensuring appropriate blood glucose monitoring and in effectively evaluating the data, and must be provided with accurate, structured data. Structured blood glucose testing allows patients and physicians to identify specific glycemic patterns that may be corrected with pharmacological or lifestyle interventions. The patterns easiest to identify and most often amenable to therapeutic intensification include hypoglycemia, fasting hyperglycemia, and postprandial hyperglycemia. Testing should be performed before and 2 hours after each meal for 3 days prior to the patient's next scheduled appointment. The difference between the baseline premeal and the 2-hour postprandial blood glucose levels is known as the "delta." The meal with the highest delta becomes the starting point for prandial insulin. ${ }^{33}$ Recent intervention studies showed that there was significant improvement in glycemic control when physicians were provided with structured self-monitoring of blood glucose data collected and recorded by patients. In addition, a recent pilot study showed that primary care physicians presented with structured, easyto-visualize self-monitoring of blood glucose data recommended more timely and aggressive treatment changes. In vulnerable patients and those with a history of hypoglycemia unawareness, diagnostic or real-time continuous glucose monitoring should be employed..$^{39}$ A recent publication in Diabetes Care found that an automated decision support tool, which analyzes self-monitoring of blood glucose data, identifies primary glycemic abnormalities, and recommends appropriate therapeutic options, was as effective as clinical information in improving clinicians' ability to interpret structured self-monitoring of blood glucose data accurately. A combination of education and decision support tool was most effective. ${ }^{40}$

In deciding upon whether to have a patient rely on self-monitoring of blood glucose or employ continuous glucose monitoring, it is important to differentiate what each method provides. Self-monitoring of blood glucose can help predict hypoglycemia, enabling the patient to make insulin dose adjustments that minimize the risk of developing hypoglycemia. On the other hand, continuous glucose monitoring provides the patient with real-time notification of an impending event by means of a preset alarm or by visually checking the device's display. ${ }^{7}$ Continuous glucose monitoring devices have three main components, ie, a disposable sensor, a transmitter, and a receiver. The sensor detects the presence of blood glucose; the transmitter, which is connected to the sensor, powers the electrochemical blood glucose reaction in the device; and the receiver records and displays the blood glucose value. The patient uses an applicator or insertion device to place a subcutaneous sensor wire. The continuous glucose monitoring device is worn for 3, 5, or 7 days, depending on the continuous glucose monitoring system used. During the wear time, the sensor's accuracy is periodically calibrated via pairing of the sensor's values with capillary blood glucose values obtained from a fingerstick.

Continuous glucose monitoring not only displays realtime interstitial blood glucose values, but sounds auditory alerts for extreme changes in blood glucose values. Patients with type 1 diabetes have evidence of dysfunctional blood glucose counter-regulation during sleep and are therefore at greater risk of developing nocturnal hypoglycemia and hypoglycemia-associated autonomic failure. ${ }^{41}$ Indices of central sympathetic activation, such as epinephrine and norepinephrine concentrations, are reduced during sleep in patients with diabetes, as are other indices, ie, heart rate, blood pressure, and peripheral vascular resistance, which drop during deeper nonrapid eye movement sleep. Impaired defenses against hypoglycemia during sleep may contribute to the vicious circle of impaired blood glucose counter-regulation when patients are either awake or asleep. Thus, both asymptomatic and symptomatic episodes of nocturnal hypoglycemia have potentially serious consequences for patients with diabetes. Any patient with a history of hypoglycemia-associated autonomic failure or nocturnal hypoglycemia should be placed on continuous glucose monitoring. ${ }^{6}$

Structured blood glucose testing also provides a useful means by which patients may learn to self-titrate their mealtime insulin doses. The fundamentals of insulin pharmacokinetics and pharmacodynamics may also be conceptualized by patients who are either new to insulin therapy or those who need a refresher course after years of insulin use. Table 6 provides some "clinically useful" tips on interpreting delta values as well as some educational strategies that may improve glycemic control.

\section{Patient education programs}

Another tool at the disposal of primary care physicians is a patient education program. These programs can help to inform patients better about the risks of hypoglycemia as well as preventive measures and treatment options. In patients who perform self-monitoring of blood glucose less 
Table 6 Interpretation of structured glucose testing readings

\begin{tabular}{|c|c|c|c|}
\hline Delta value (mg/dL) & Delta value ( $\mathrm{mmol} / \mathrm{L})$ & Interpretation & Intervention \\
\hline $0-50$ & $0-2.7$ & $\begin{array}{l}\text { - Correct insulin given for amount of } \\
\text { carbohydrates consumed } \\
\text { - Correct lag time procedure followed }\end{array}$ & - None \\
\hline $51-100$ & $2.8-5.5$ & $\begin{array}{l}\text { - Insulin-to-carbohydrate mismatch } \\
\text { - Incorrect lag time } \\
\text { - Possible snacking in between end } \\
\text { of meal and 2-hour test }\end{array}$ & $\begin{array}{l}\text { - Increase prandial insulin dose } \\
\mathrm{I}-2 \text { units next time this type } \\
\text { of food is eaten } \\
\text { - Make sure to inject insulin at } \\
\text { least } 15 \text { minutes prior to meals }\end{array}$ \\
\hline $100-200$ & $5.5-11.1$ & $\begin{array}{l}\text { Possibly had elevated blood glucose } \\
\text { prior to mealtime and did not give } \\
\text { a correction dose } \\
\text { - Insulin-to-carbohydrate mismatch } \\
\text { - Was insulin omitted? } \\
\text { - Errors in blood glucose monitoring } \\
\text { technique }\end{array}$ & $\begin{array}{l}\text { - Teach patient how to use a } \\
\text { premeal insulin sensitivity factor } \\
\text { - If patient omitted insulin they } \\
\text { will see the error of their ways } \\
\text { - If postmeal delta is consistently } \\
\text { elevated, increase baseline } \\
\text { insulin dose by I unit per day } \\
\text { until delta is } 0-2.7 \mathrm{mmol} / \mathrm{L} \\
(0-50 \mathrm{mg} / \mathrm{dL}) \text { or } 2 \text {-hour } \\
\text { postprandial blood glucose } \\
\text { value is } 7.7 \mathrm{mmol} / \mathrm{L} \\
\text { ( }<140 \mathrm{mg} / \mathrm{dL}) \\
\text { - Educate patient on proper BG } \\
\text { monitoring. Touching fruit, cakes, } \\
\text { or ice cream after a meal may } \\
\text { result in false elevation of BG } \\
\text { values }\end{array}$ \\
\hline $\begin{array}{l}\text { Any negative delta value } \\
(e g,-25)\end{array}$ & Any negative delta value & $\begin{array}{l}\text { - Miscalculation of insulin-to-carbohydrate } \\
\text { ratio: too much insulin administered for } \\
\text { amount of carbohydrate eaten. Patient } \\
\text { is likely to become hypoglycemic in the } \\
\text { next I-2 hours }\end{array}$ & $\begin{array}{l}\text { Educate patient regarding insulin } \\
\text { absorption principles: I hour } \\
\text { after bolus administration, } 90 \% \\
\text { of rapid-acting insulin analog } \\
\text { remains in depot. Based upon } \\
\text { the pharmacokinetics of rapid- } \\
\text { acting insulins (lispro, aspart, } \\
\text { and glulisine), the percentage of } \\
\text { insulin remaining to be absorbed } \\
\text { from the depot postbolus are as } \\
\text { follows: } 90 \% \text { at I hour, } 60 \% \text { at } \\
2 \text { hours, and } 40 \% \text { at } 3 \text { hours. } \\
\text { Thus, if } 10 \text { units of insulin are } \\
\text { given at } 8 \text { am, at } 10 \text { am } 6 \text { units } \\
\text { ( } 60 \% \text { of the initial bolus) remains } \\
\text { to be absorbed. A premeal blood } \\
\text { glucose value of } 6.6 \text { mmol/L } \\
\text { ( } 120 \mathrm{mg} / \mathrm{dL} \text { ) and a } 2 \text {-hour } \\
\text { postmeal blood glucose value of } \\
4.9 \mathrm{mmol} / \mathrm{L} \text { ( } 90 \text { mg/dL) gives a } \\
\text { delta of }-\mathrm{I} .6 \mathrm{mmol} / \mathrm{L} \text { ( }-30 \mathrm{mg} / \mathrm{dL} \text { ). } \\
\text { Because } 6 \text { units of rapid-acting } \\
\text { insulin remains to be absorbed, } \\
\text { a significant decline in blood } \\
\text { glucose has been noted at } \\
2 \text { hours after eating, and the } \\
\text { patient is trending towards } \\
\text { hypoglycemia. Self-monitoring } \\
\text { should be repeated at } 3 \text { and } \\
4 \text { hours postinjection to identify } \\
\text { and correct any hypoglycemia } \\
\text { ( }<3.3 \mathrm{mmol} / \mathrm{L} \text { [ }<60 \text { mg/dL]) } \\
\text { events proactively }\end{array}$ \\
\hline
\end{tabular}

Abbreviation: BG, blood glucose. 
than optimally, which is a common issue, these programs can also help to educate patients about the importance of frequent self-monitoring of blood glucose, good recordkeeping, and communication with the primary care physician to improve the accuracy of the blood glucose information that they provide.

Patient education programs can also help to reduce patient fear of hypoglycemia and improve diabetes management. As mentioned previously, HFS data indicate that previous episodes of severe hypoglycemia, or negative preconceptions about insulin-based treatment regimens, can significantly influence patient worries and behaviors about hypoglycemia, and fear of hypoglycemia has a significant clinical impact on diabetes management, metabolic control, and long-term health outcomes. ${ }^{26}$ There is evidence that blood glucose awareness training and cognitive behavioral therapy can help to improve diabetic management, and that interventions targeting health beliefs and attitudes about hypoglycemia and diabetes self-management can be more effective than knowledge-centered patient education, which focus on "symptom perception", in reducing hypoglycemia unawareness. ${ }^{42}$

\section{Titration algorithms}

Because hypoglycemic events are more common during the titration period of insulin-based therapies, carefully implemented insulin titration algorithms can also be employed when adding basal insulin to the patient's treatment regimen. This has been shown to enable better glycemic control, with little risk of severe hypoglycemia. ${ }^{43}$ The patient should be actively involved in the titration process and should be provided with self-dosing titration algorithms for both basal and prandial insulin.

\section{Advances in insulin therapy}

In spite of the hypoglycemic risks associated with intensive treatment regimens, current diabetes guidelines continue to emphasize their importance, and the pursuit of tighter glycemic control has led to earlier and more intensive use of insulin. ${ }^{7,10}$ Over time, most patients with type 2 diabetes will need to initiate insulin therapy to maintain adequate blood glucose levels. In fact, patients with type 2 diabetes may often benefit substantially from earlier introduction of insulin, but it is delayed due to substantial fear of hypoglycemia. These facts have led to the development of ever-improving insulin analogs and insulin-based therapies, which provide adequate glycemic control while limiting the attendant risk of frequent and/or severe hypoglycemia.

Insulin was first used in the treatment of diabetes in the 1920s. By the 1940s, the need for a prolonged duration of action had driven the development of neutral protamine Hagedorn (NPH) insulin, which has a neutral protamine added to the insulin, thereby giving it an extended duration of action. NPH is an intermediate-acting insulin which is prone to a dome-shaped basal plasma profile, which leaves the patient vulnerable to hypoglycemic events at the peak of insulin action. The 1980s saw the introduction of human insulin, which displays suboptimal pharmacodynamic and pharmacokinetic properties. More recently, advances in molecular biology have allowed the development of insulin analogs, the pharmacokinetic and pharmacodynamic profiles of which more closely match that of endogenous insulin in a healthy individual (Figure 3) ${ }^{44} \mathrm{An}$ array of clinical trials and observational studies has examined the efficacy and safety of the insulin analogs. They have consistently been shown to provide as good or better glycemic control than human or NPH insulin and to reduce the risk of hypoglycemia in both

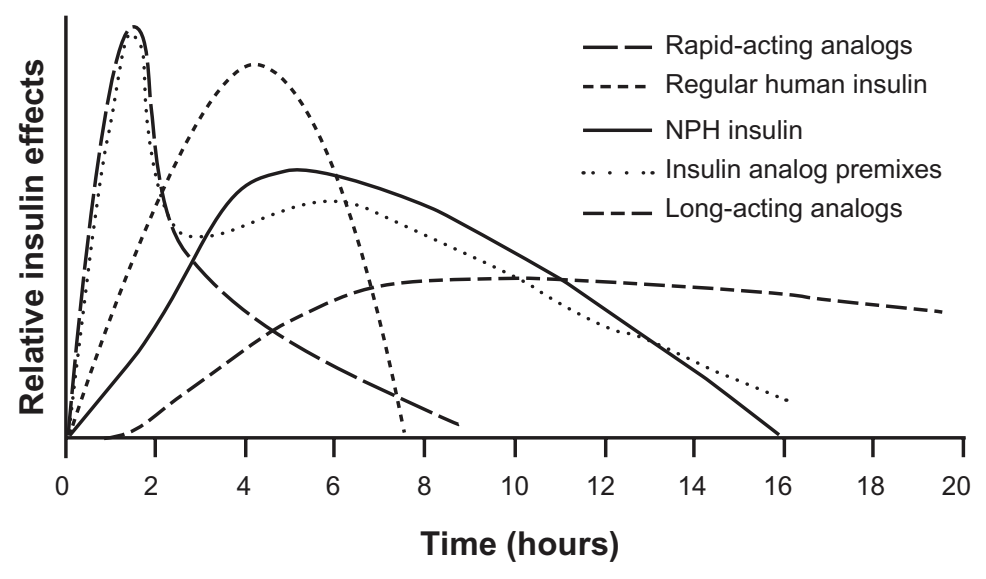

Figure 3 Action profile of rapid-acting and long-acting insulin analogs and insulin analog premixes.

Copyright (c) 2009, UBM Medica LLC. Reprinted with permission from Brunton S. Safety and effectiveness of modern insulin therapy: the value of insulin analogs. Consultant. 2009;Suppl:SI3-S19. 
type 1 and type 2 diabetes patients in controlled trials and in clinical practice. However, clinical trials of insulins have typically employed a "treat-to-target" principle, whereby instead of examining fixed drug doses, investigators titrate the drugs under investigation to achieve a fixed treatment target; in the case of diabetes trials, this is typically a specific $\mathrm{HbA}_{1 \mathrm{c}}$ target. This better enables the investigators to assess adverse events, such as hypoglycemia.

\section{The ideal insulin}

A number of recently created insulin analogs and those still under development and in clinical trials are designed specifically to address several unmet needs, with the intention to create the ideal insulin that will provide optimal glycemic control, with limited adverse effects, and improved convenience to the patient. Typically, insulin therapy comprises a long-acting basal insulin, which mimics the background insulin normally produced over a 24 -hour period by the pancreas, supplemented with a bolus or short-acting insulin, which mimics the normal physiological insulin response to ingestion of a meal.

Several key characteristics of the ideal insulin have been identified, which are guiding the development of new insulin analogs and treatment regimens. Among the most important of these aspects is minimal intrapatient variability (the same dose given on different occasions should give the same effect); reduced risk of hypoglycemia (the insulin[s] should display a flat pharmacodynamic profile associated with a low risk of hypoglycemia or peak relatively quickly to cover meals, in the case of fast-acting analogs); ease of administration (with the focus on reducing the number of daily injections and improving accuracy of dosing to improve adherence and avoid hypoglycemic events); flexible administration times (the insulin[s] should be adaptable to the patient's needs, particularly for patients with irregular diet or work schedules); and superior fasting and postprandial blood glucose control (the control of fasting blood glucose is equally important to postprandial blood glucose control to reduce the risk of microvascular and macrovascular complications). ${ }^{45,46}$

\section{Long-acting basal insulin analogs}

Various efforts have been made to develop insulin analogs that closely mimic the pharmacokinetic profile of endogenous insulin. Among them are long-acting insulins, which serve to mimic the basal action of insulin over a 24-hour period. ${ }^{46}$ Insulin glargine and insulin detemir are both long-acting insulins, with flatter insulin profiles that more closely match normal basal insulin release. Both gained FDA approval for use in patients with diabetes in the early part of the last decade (insulin glargine in 2000 and insulin detemir in 2005). Their duration of action is between 18 and 26 hours, compared with approximately 14.5 hours for NPH insulin.7,46 They can be administered 1-2 times daily for basal insulin supply. Both are longer-acting than NPH insulin, but insulin detemir has the added advantage of less intrapatient variability than both insulin glargine and NPH insulin, which have a similar level of variability (GIR-AUC ${ }_{(0-12 \mathrm{~h})} 27 \%$ [detemir] versus $59 \%$ [NPH] versus 46\% [glargine], as assessed by the coefficient of variation for the pharmacodynamic end points studied). ${ }^{47}$ A major advantage of these long-acting insulins is that they achieve similar if not better levels of glycemic control when studied in a treat-to-target study design, while presenting a substantially lower risk of overall hypoglycemic events, in both type 1 and type 2 diabetes patients. Patients treated with insulin glargine experience a $46 \%$ reduction in severe and 59\% reduction in nocturnal hypoglycemia, compared with those treated with NPH insulin, ${ }^{46}$ while treatment with insulin detemir is associated with fewer mild hypoglycemic events than NPH insulin (mean rate 26.3 versus 35.5 events per subject over one year). Furthermore, a model developed to evaluate cost-effectiveness based on mild hypoglycemia and pharmacy costs over one year found that, although insulin detemir was associated with higher pharmacy costs, it was likely to be more cost-effective than NPH insulin in subjects with type 1 diabetes as the result of a reduction in mild hypoglycemia. ${ }^{48}$ Patients treated with insulin detemir also experience a $87 \%-90 \%$ decrease in nocturnal hypoglycemia. ${ }^{46}$ In insulin-naïve patients with type 2 diabetes, basal insulin analogs lower the risk of all hypoglycemic events when compared with NPH insulin (16\% versus $26 \%$, respectively). ${ }^{38}$ They also demonstrate fewer hypoglycemic events than rapid-acting analogs and premixed formulations, which will be discussed in the following sections, and therefore offer maximum tolerability among the insulin regimens.

The biggest disadvantage with the currently available basal insulins is that they have to be injected at a consistent time every day in order to ensure optimal biological action, and in some patients need to be dosed twice daily to provide 24 hours of blood glucose control. Patients may have difficulty adhering to these strict dosing schedules. For this reason, a new ultra long-acting insulin has recently been submitted to the FDA for review, ie, insulin degludec. Insulin degludec is an ultra long-acting novel insulin preparation, the action profile of which is primarily attributable to the formation of soluble multihexamers at the injection site. 
Inside the insulin pen, the insulin dihexamers are bound by phenol. Following an injection into the subcutaneous depot, the phenol is dispersed, allowing the hexamers to disassociate and be absorbed from the interstitial space. The insulin degludec monomers are bound to the multiheximers by zinc. The zinc gradually separates from the multihexamers resulting in a slow, continuous and predictable delivery of insulin degludec monomers from the subcutaneous injection depot into the circulation. ${ }^{49}$ The monomers are reversibly bound to albumin and carried to their receptor sites in the periphery. Once steady state is reached, the mean half-life is 25.1 hours $^{50}$ and the duration of action is up to 42 hours. ${ }^{51}$ Insulin degludec reduced the risk of confirmed nocturnal hypoglycemia when compared with insulin glargine in patients with type 1 diabetes $^{52}$ and reduced the risk of confirmed nocturnal and confirmed overall hypoglycemia when compared with insulin glargine in patients with type 2 diabetes. ${ }^{53}$

The safety and efficacy of the prolonged half-life of insulin degludec has been tested by using extreme dosing intervals of 8-40 hours in patients with type 2 diabetes and comparing their $\mathrm{HbA}_{1 \mathrm{c}}$ levels and safety data with those from patients receiving insulin glargine injected at the same time each day for 26 weeks. ${ }^{54}$ Both the insulin degludec and glargine patients demonstrated similar reductions from baseline $\mathrm{HbA}_{1 \mathrm{c}}(-1.28 \%$ and $-1.26 \%$ points, respectively). The mean fasting blood glucose at week 26 was significantly lower for insulin degludec than for glargine (5.8 versus $6.2 \mathrm{mmol} / \mathrm{L}$ [104 versus $112 \mathrm{mg} / \mathrm{dL}$ ]; $P=0.04)$. The mean daily doses of the two insulins were similar between groups, as were rates of confirmed and nocturnal hypoglycemia. ${ }^{54}$ Thus, flexible dosing at any time of day does not compromise glycemic control or increase the risk of hypoglycemia in patients with type 2 diabetes when compared with insulin glargine. From a clinical perspective, the flexibility of insulin degludec may be useful for patients who travel, are shift workers, or prefer to sleep later on weekends without having to worry about developing hyperglycemia if the timing of their routine insulin injections is disrupted.

\section{Rapid-acting bolus insulin analogs}

A number of rapid-acting insulin analogs have also been developed to mimic more closely the mealtime insulin response. These include insulin lispro, insulin aspart, and insulin glulisine, which are quickly absorbed into the system, and have a rapid onset, and a short duration of action. In this way, they reduce postprandial blood glucose excursions and help to lessen the risk of hypoglycemia in the periods between meals. Overall, patients taking rapid-acting insulin analogs experience far fewer episodes of all types of hypoglycemia compared with those on human insulin. A Cochrane review of clinical studies clearly illustrated this reduction in hypoglycemic risk, finding a median 21.8 episodes per 100 person-years in type 1 diabetes and 0.3 in type 2 diabetes, for rapid-acting insulin analogs, compared with 46.1 episodes per 100 personyears in type 1 diabetes and 4.1 in type 2 diabetes for human insulin. ${ }^{55}$ Rapid-acting analogs are also particularly effective at reducing the risk of nocturnal hypoglycemia. For example, one study found that $1.3 \%$ of patients experienced major nocturnal hypoglycemic events with insulin aspart versus $3.4 \%$ of patients with human insulin. ${ }^{56}$ Another study found that only 52 patients experienced nocturnal hypoglycemia with insulin lispro, compared with 181 patients with human insulin. ${ }^{57}$ Data assessing the effect of insulin glulisine on the risk of hypoglycemia are less abundant; however, it has been shown to have effects comparable with those of insulin lispro, with 3.64 symptomatic hypoglycemic events per patient-month, compared with 3.48 for insulin lispro. ${ }^{58}$ Rapid-acting insulins have the lowest intrapatient variability compared with human insulin and intermediate and long-acting insulins. ${ }^{59}$ These insulin analogs also offer much greater patient flexibility in dosing times, allowing dosing at or even during mealtimes, compared with 30 minutes prior to a meal with human insulin.

\section{Biphasic insulin analog premixes}

Normally, patients with diabetes need to take multiple bolus injections and a basal injection each day. The number of injections facing patients with diabetes on this regimen is a significant barrier to adherence. The need for a convenient, effective, and simultaneous supplementation of basal and bolus insulin with fewer injections led to the development of premixed formulations of biphasic human insulin, containing a combination of a short-acting and intermediate acting insulin in standard proportions.

With the development of insulin analogs, newer premixes have become available that incorporate these analogs. While human premixed formulations contain $70 \% \mathrm{NPH}$ and $30 \%$ regular human insulin as the basal and prandial components, respectively, biphasic insulin analogs, in contrast, consist of a mixture of a rapid-acting insulin analog and its intermediateacting protaminated form as the basal component. These include biphasic insulin aspart (70/30), biphasic insulin lispro (75/25), and biphasic insulin lispro (50/50).

In general, biphasic insulins should be used with caution in patients with less structured lifestyles and eating habits, ${ }^{7}$ but they do offer a number of advantages. First, they demonstrate 
improved glycemic control compared with human insulin premixes and basal insulins. They also improve patient adherence with therapeutic regimens, because they reduce the number of injections and require less monitoring compared with basal-bolus therapy. The rapid-acting component more closely mimics the physiological mealtime profile of insulin, and is more rapidly absorbed and cleared from the system, thus biphasic insulin analogs can be administered closer to mealtimes. Finally, though the human insulin premixes and insulin analog premixes exhibit the same number of minor hypoglycemic events (approximately 60\%), the insulin analog premixes have been reported to reduce the risk of major hypoglycemic events compared with premixed human insulin. ${ }^{44}$ For example, a 12-week study of patients with type 1 or type 2 diabetes showed that patients treated with biphasic insulin aspart experienced half as many major hypoglycemic episodes compared with those treated with biphasic human insulin (20 versus 42 episodes), although the overall risk of either major or minor hypoglycemia did not differ significantly between treatments. ${ }^{60}$ When the study was extended to 2 years in patients with type 2 diabetes, the proportion of patients experiencing major hypoglycemia was significantly lower at year 2 (biphasic insulin aspart 0\%, biphasic human insulin, $10 \% ; P=0.04) .{ }^{61}$ When measured using a continuous glucose monitoring system, nocturnal hypoglycemia has also been reported to occur less frequently with insulin analog premixes than with premixed human insulin $(6.4 \%$ of time versus $7.9 \%$, respectively; $P=0.018) .{ }^{62}$

The physiochemical properties of the current basal analogs (glargine and detemir) do not allow for a true combination of a rapid-acting insulin with a basal insulin analog, because this combination is incompatible. Thus, the premixes and biphasic insulins brought to the market to date have always used the combination of a single insulin, with the addition of protamine creating the biphasic/mix properties. The ultra long-acting insulin degludec, which is currently under development, for the first time allows the generation of a true combination of a basal insulin and a rapid-acting analog. Insulin degludec/insulin aspart is a soluble coformulation of insulin degludec (70\%) and insulin aspart (30\%). In a study comparing the coformulation with insulin glargine, 70/30 degludec/aspart provided overall glycemic control comparable with that of insulin glargine, with similar low rates of hypoglycemia. ${ }^{63}$

\section{Advances in insulin delivery}

Typically in the US, insulin is injected with a syringe and vial, and there are two main modes of administration, ie, multiple daily injection, where patients inject a fixed amount of insulin, and continuous subcutaneous insulin injection, which allows for incremental insulin administration and more physiological insulin delivery. The general belief is that intensive insulin administration is associated with increased hypoglycemic risk, but studies have shown that in fact there is a significant decrease in the risk of hypoglycemia with continuous subcutaneous insulin injection when compared with multiple daily injection. ${ }^{7}$ However, continuous subcutaneous insulin injection poses a substantial financial and personal commitment.

The ultimate challenge in treating insulin-requiring diabetes is to design a reliable "closed-loop" sensor-augmented insulin pump. These insulin delivery devices incorporate data transmitted from real-time continuous interstitial blood glucose sensors directly to the insulin pump. The patient will receive an infusion of insulin commensurate with ambient interstitial blood glucose readings.

The safety and efficacy of the sensor-augmented pump was evaluated in the 1-year randomized phase of the SensorAugmented Pump Therapy for A1C Reduction (STAR) 3 study in patients with type 1 diabetes. ${ }^{64}$ Compared with subjects using multiple daily injections, those using sensoraugmented pump experienced greater reductions in $\mathrm{HbA}_{1 \mathrm{c}}$ levels by 3 months, which persisted for the duration of the study. A group of patients on multiple daily injections within STAR 3 were allowed to switch to sensor-augmented pump therapy for 6 months at the conclusion of the one-year trial. ${ }^{65}$ Patients on the sensor-augmented pump were also allowed to remain on their therapy for an additional 6 months, extending the STAR 3 study to 18 months. Of the 443 patients who completed the one-year study, 420 elected to continue for an additional 6 months. Two hundred and four (94\%) of the patients on the sensor-augmented pump continued their initial augmented pump therapy, while 190 (93\%) of the subjects on multiple daily injections decided to cross over to the sensor-augmented pump group.

During the study phase of STAR 3, the $\mathrm{HbA}_{1 \mathrm{c}}$ levels were reduced by approximately $0.5 \%-0.6 \%$ more with sensoraugmented pump treatment compared with multiple daily injections. Patients switching from multiple daily injections to the sensor-augmented pump during the continuation phase reduced their $\mathrm{HbA}_{1 \mathrm{c}}$ levels by a similar percentage. Patients who wore the sensor at least $60 \%$ of the time demonstrated maximal lowering of $\mathrm{HbA}_{1 \mathrm{c}}$ levels.

The sensor-augmented pump technology has also demonstrated efficacy in automatically suspending basal insulin delivery for up to 2 hours in response to sensor-detected 
hypoglycemia in patients with type 1 diabetes. ${ }^{66}$ The ability of the sensor to suspend insulin delivery automatically without patient intervention is an important step in closing the loop.

Another development in the administration of insulin is the introduction of pen injector systems. There are two types of pen devices, which have either replaceable or prefilled cartridges, the latter of which can be completely disposed of (including the pen) when empty. Pen injectors have been shown to improve ease of administration, patient satisfaction. and adherence (by up to $75 \%-80 \%$ ), and allow more precise dosing in a single injection. ${ }^{67}$ The 32 -gauge needles used in the delivery of insulin in these injector pens are virtually painless. ${ }^{33}$ Switching from a syringe and vial to an injector pen has also been shown to reduce the risk of hypoglycemic events by $50 \%,{ }^{68}$ as well as to reduce the cost associated with hypoglycemia (see Table 3). ${ }^{29}$ Insulin titration may be better performed using a pen injector because this device can provide accurate titrations of one-unit increments of insulin per meal with a simple twist of the dial. ${ }^{33}$ In spite of the advantages, the use of pen devices in the US remains low in comparison with other developed countries, with only $15 \%$ of patients thought to use them. ${ }^{67}$

Given that errors in insulin administration remain high, pens may provide a clear opportunity for increasing insulin safety and reducing the risk of accidental iatrogenic hypoglycemia. A retrospective search, for example, was performed for all records related to unintentional insulin overdoses at nine poison centers in four US states (Kentucky, Louisiana, Texas, and Kansas, comprising a pool of 36 million people) for the years 2000-2009. ${ }^{69}$ Unintentional therapeutic errors were defined as any insulin provided in a manner that is an unintentional deviation from a proper therapeutic regimen and results in an incorrect route of administration, wrong dose, administration to the wrong person, or administration of the wrong substance. As reported to the nine poison centers, there were 2584 unintentional therapeutic errors involving insulin. During this 10-year reporting period, there was a $495 \%$ increase in the annual incidence of unintentional therapeutic errors involving insulin, with a mean annual increase of $28 \%$.

As the diabetes population ages, physicians must consider prescribing insulin that can be administered in the safest and most effective manner. In addition, patients are more frequently being provided the opportunity to selftitrate their basal and prandial insulin doses ambitiously in order to achieve their targeted glycemic levels in a timely manner. Pen devices allow patients to self-titrate their doses of insulin safely and accurately. Pen devices are color-coded and texture-coded, which minimizes the risk of confusion as to which injections are provided as basal, mixed, or prandial insulin. New-generation pens will provide a reduction in injection force and dosing accuracy over a broad range of insulin doses. ${ }^{70}$

\section{Alternative treatment strategies}

Other developments in options for the treatment of diabetes address the need for reducing hypoglycemic risk while maintaining optimal glycemic control. These include the incretins, gastrointestinal hormones that stimulate postprandial release of insulin from $\beta$-cells. The incretin system can be pharmacologically influenced in two different ways, ie, via glucagon-like peptide-1 receptor agents, including exenatide and liraglutide, and dipeptidyl peptidase-4 inhibitors (dipeptidyl peptidase-4 regulates glucagon-like peptide-1 activity), which include sitagliptin, vildagliptin, and saxagliptin, among others. The so-called "incretin effect" is responsible for $50 \%-70 \%$ of postprandial insulin release in healthy individuals.

The incretins have the advantage of an extremely low hypoglycemic risk when used as monotherapy. However, it is important to remember that this feature may be lost, and hypoglycemia may occur when these agents are used in combination with insulin or insulin secretagogues such as sulfonylureas. For example, exenatide has a 5\% hypoglycemic risk as a monotherapy, which increases to $35 \%$ when combined with a sulfonylurea. ${ }^{71}$ Combination therapy of incretins with basal insulin can also be effective for insulinnaïve patients with type 2 diabetes whose disease is suboptimally controlled with oral agents. ${ }^{72,73}$ In October, 2011, the FDA approved the use of exenatide as an addon therapy to insulin glargine, with or without metformin or thiazolidinedione, in conjunction with diet and exercise for adults with type 2 diabetes. In a study examining the expanded use of exenatide, 261 patients receiving insulin glargine, with or without metformin or a thiazolidinedione, were randomly assigned to receive $10 \mu \mathrm{g}$ of exenatide $(\mathrm{n}=138)$ or placebo $(\mathrm{n}=123)$ and were stratified by baseline $\mathrm{HbA}_{1 \mathrm{c}}$ level $(\leq 8 \%$ or $>8 \%) .{ }^{72}$ At randomization, patients with an $\mathrm{HbA}_{1 \mathrm{c}}$ level $\leq 8 \%$ had their insulin glargine dose reduced by $20 \%$.

After 5 weeks, all patients underwent aggressive insulin titration to a target fasting blood glucose of $<5.6 \mathrm{mmol} / \mathrm{L}$ $(<100 \mathrm{mg} / \mathrm{dL})$. At 30 weeks, $\mathrm{HbA}_{1 \mathrm{c}}$ reduction from baseline with exenatide plus insulin glargine was greater than with glargine alone $(-1.74 \%$ points versus $-1.04 \%$ points; $P<0.001)$. In addition, $60 \%$ of patients in the exenatide 
group versus $35 \%$ in the glargine-alone group achieved a target $\mathrm{HbA}_{1 \mathrm{c}}$ level of $\leq 7 \%(P<0.001)$. Further, $40 \%$ of patients using exenatide versus $12 \%$ of patients using glargine alone achieved a target $\mathrm{HbA}_{1 \mathrm{c}}$ of $\leq 6.5 \%$ ( $\left.P<0.001\right)$. All patients had lower fasting blood glucose concentrations, although patients receiving exenatide had generally improved postprandial blood glucose control compared with patients in the placebo group. Patients in the exenatide arm also lost an average of $1.8 \mathrm{~kg}(4 \mathrm{lb})$, whereas patients in the insulin glargine-only arm gained $1 \mathrm{~kg}(2.2 \mathrm{lb} ; P<0.001)$. No increased risk for hypoglycemia was noted in the exenatide group, and nausea was the most commonly reported adverse event. $^{72}$

Used as monotherapy or in combination with other blood glucose-lowering agents, incretins would be most beneficial in patients with type 2 diabetes mellitus who have multiple comorbidities, elderly patients who live alone, or patients at high risk of falls, because these patients may be unable to respond appropriately to an episode of severe hypoglycemia or may be at increased risk of hypoglycemia unawareness. ${ }^{6,74}$

\section{Conclusion}

Iatrogenic hypoglycemia represents a much more substantial barrier to the effective control of blood glucose concentrations in patients with diabetes than is currently appreciated. Greater awareness and detection of all hypoglycemic events by careful monitoring, adherence to guidelines, and use of optimal treatment combinations is needed in order to prevent the serious medical and economic consequences associated with this adverse effect of antihyperglycemic medications. There is a need for improved patient and provider education on optimal detection and understanding of hypoglycemia and the benefits of accurate blood glucose measurement, which together can help to reduce the risk and fear of hypoglycemia, hypoglycemia unawareness, and hypoglycemic events.

Intensive insulin regimens are required in order to meet tighter glycemic goals, but carry an inherently increased risk of hypoglycemia. Though much progress has been made in recent years with the introduction of rapid-acting insulin analogs and biphasic premixes, there is a continuing need for newer therapeutic agents that carry lower risks of hypoglycemia, while maintaining optimal glycemic control and improving patient adherence. Therapeutic advances are continually being made, and insulins that ever more closely match the physiological profile of human insulin are on the horizon.

\section{Disclosure}

Emma Hitt of MedVal Scientific Information Services, LLC, provided medical writing and editorial assistance with this manuscript, which was prepared according to the International Society for Medical Publication Professionals "Good Publication Practice for Communicating Company-Sponsored Medical Research: the GPP2 Guidelines." Funding to support the preparation of this manuscript was provided by Novo Nordisk Inc. The author has received clinical research grants from Abbott, Boehringer Ingelheim, Eli Lilly, Forrest, Novo Nordisk, Pfizer, and sanofi-aventis. He has also served as an advisor/consultant for Novo Nordisk Inc, and has been a speaker for Abbott, Boehringer Ingelheim, Eli Lilly, Novo Nordisk Inc, and Roche. The author received no financial compensation for his work on preparing, writing, and editing this manuscript.

\section{References}

1. Cryer PE. Hypoglycaemia: the limiting factor in the glycaemic management of type I and type II diabetes. Diabetologia. 2002; 45(7):937-948

2. UK Prospective Diabetes Study Group. Intensive blood-glucose control with sulphonylureas or insulin compared with conventional treatment and risk of complications in patients with type 2 diabetes (UKPDS 33). Lancet. 1998;352(9131):837-853.

3. Zoungas S, Patel A, Chalmers J, et al. Severe hypoglycemia and risks of vascular events and death. $N$ Engl J Med. 2010;363(15): 1410-1418

4. Cryer PE. Hypoglycemia in Diabetes: Pathophysiology, Prevalence, and Prevention. Alexandria, VA: American Diabetes Association; 2009

5. Cryer PE, Davis SN, Shamoon H. Hypoglycemia in diabetes. Diabetes Care. 2003;26(6):1902-1912.

6. Unger J, Parkin C. Hypoglycemia in insulin-treated diabetes: a case for increased vigilance. Postgrad Med. 2011;123(4):81-91.

7. Unger J, Parkin C. Recognition, prevention, and proactive management of hypoglycemia in patients with type 1 diabetes mellitus. Postgrad Med. 2011;123(4):71-80.

8. Amiel SA, Dixon T, Mann R, Jameson K. Hypoglycaemia in type 2 diabetes. Diabet Med. 2008;25(3):245-254.

9. American Diabetes Association. Defining and reporting hypoglycemia in diabetes: a report from the American Diabetes Association Workgroup on Hypoglycemia. Diabetes Care. 2005;28(5):1245-1249.

10. American Diabetes Association. Standards of medical care in diabetes 2012. Diabetes Care. 2012;35 Suppl 1:S11-S63.

11. US Food and Drug Administration. Guidance for industry: diabetes mellitus - developing drugs and therapeutic biologics for treatment and prevention. Rockville, MD: US Food and Drug Administration; 2008.

12. Leese GP, Wang J, Broomhall J, et al. Frequency of severe hypoglycemia requiring emergency treatment in type 1 and type 2 diabetes: a population-based study of health service resource use. Diabetes Care. 2003;26(4):1176-1180.

13. Donnelly LA, Morris AD, Frier BM, et al. Frequency and predictors of hypoglycaemia in type 1 and insulin-treated type 2 diabetes: a population-based study. Diabet Med. 2005;22(6):749-755.

14. UK Hypoglycaemia Study Group. Risk of hypoglycaemia in types 1 and 2 diabetes: effects of treatment modalities and their duration. Diabetologia. 2007;50(6):1140-1147. 
15. Brod M, Christensen T, Thomsen TL, Bushnell DM. The impact of non-severe hypoglycemic events on work productivity and diabetes management. Value Health. 2011;14(5):665-671.

16. Janssen MM, Snoek FJ, de Jongh RT, Casteleijn S, Deville W, Heine RJ. Biological and behavioural determinants of the frequency of mild, biochemical hypoglycaemia in patients with type 1 diabetes on multiple insulin injection therapy. Diabetes Metab Res Rev. 2000; 16(3):157-163.

17. Fisher M. Hypoglycaemia in patients with type 2 diabetes: minimising the risk. Br J Diabetes Vasc Dis. 2010;10:35-41.

18. McNay EC, Cotero VE. Mini-review: impact of recurrent hypoglycemia on cognitive and brain function. Physiol Behav. 2010;100(3): 234-238.

19. Warren RE, Frier BM. Hypoglycaemia and cognitive function. Diabetes Obes Metab. 2005;7(5):493-503.

20. Whitmer RA, Karter AJ, Yaffe K, Quesenberry CP Jr, Selby JV. Hypoglycemic episodes and risk of dementia in older patients with type 2 diabetes mellitus. JAMA. 2009;301(15):1565-1572.

21. ACCORD Study Group. Effects of intensive glucose lowering in type 2 diabetes. N Engl J Med. 2008;358(24):2545-2559.

22. Gerstein HC, Miller ME, Genuth S, et al; ACCORD Study Group. Long-term effects of intensive glucose lowering on cardiovascular outcomes. N Engl J Med. 2011;364(9):818-828.

23. Turnbull FM, Abraira C, Anderson RJ, et al. Intensive glucose control and macrovascular outcomes in type 2 diabetes. Diabetologia. 2009;52(11):2288-2298.

24. Bonds DE, Miller ME, Bergenstal RM, et al. The association between symptomatic, severe hypoglycaemia and mortality in type 2 diabetes: retrospective epidemiological analysis of the ACCORD study. $\mathrm{Br} \mathrm{Med} \mathrm{J}$. 2010;340:b4909.

25. Schopman JE, Geddes J, Frier BM. Frequency of symptomatic and asymptomatic hypoglycaemia in type 1 diabetes: effect of impaired awareness of hypoglycaemia. Diabet Med. 2011;28(3):352-355.

26. Wild D, von Maltzahn R, Brohan E, Christensen T, Clauson P, Gonder-Frederick L. A critical review of the literature on fear of hypoglycemia in diabetes: implications for diabetes management and patient education. Patient Educ Couns. 2007;68(1):10-15.

27. Gonder-Frederick LA, Schmidt KM, Vajda KA, et al. Psychometric properties of the Hypoglycemia Fear Survey-II for adults with type 1 diabetes. Diabetes Care. 2011;34(4):801-806.

28. Tupola S, Rajantie J, Akerblom HK. Experience of severe hypoglycaemia may influence both patient's and physician's subsequent treatment policy of insulin-dependent diabetes mellitus. Eur J Pediatr. 1998;157(8):625-627.

29. Zhang Y, Wieffer H, Modha R, Balar B, Pollack M, Krishnarajah G The burden of hypoglycemia in type 2 diabetes: a systematic review of patient and economic perspectives. $J$ Clin Outcomes Manage. 2010;17(12):547-557.

30. Frier BM. The economic costs of hypoglycaemia. Br J Diabetes Vasc Dis. 2011;11 Suppl 1:10-12.

31. Harris SB, Leiter LA, Yale J-F, Chaisson J-L, Kleinstiver P, Sauriol L. Out of pocket costs of managing hyperglycemia and hypoglycemia in patients with type 1 diabetes and insulin-treated type 2 diabetes. Can J Diabetes. 2007;31(1):25-33.

32. Curkendall SM, Zhang B, Lenhart GM, et al. Impact of hypoglycemia events on short-term disability and absenteeism in patients with type 2 diabetes [Abstract]. Diabetes. 2011;60 Suppl 1: A549-A573.

33. Unger J. Insulin initiation and intensification in patients with type 2 diabetes mellitus for the primary care physician. Diabetes Metab Syndr Obes. 2011;4:253-261.

34. California Healthcare Foundation/American Geriatrics Society. Guidelines for improving the care of the older person with diabetes mellitus. J Am Geriatr Soc. 2003;51(Supp1 5):S265-S280.

35. Munshi MN, Segal AR, Suhl E, et al. Frequent hypoglycemia among elderly patients with poor glycemic control. Arch Intern Med. 2011;171(4):362-364.
36. Diabetes Control and Complications Trial Research Group. The effect of intensive treatment of diabetes on the development and progression of long-term complications in insulin-dependent diabetes mellitus. The Diabetes Control and Complications Trial Research Group. N Engl J Med. 1993;329(14):977-986.

37. Hoelzel W, Miedema K. Development of a reference system for the international standardization of HbA1c/glycohemoglobin determinations. J Int Fed Clin Chem. 1996;9(2):62-67.

38. Hermansen K, Davies M, Derezinski T, Ravn GM, Clauson P, Home P. A 26-week, randomized, parallel, treat-to-target trial comparing insulin detemir with NPH insulin as add-on therapy to oral glucose-lowering drugs in insulin-naïve people with type 2 diabetes. Diabetes Care. 2006;29(6):1269-1274.

39. Polonsky WH, Fisher L, Schikman CH, et al. A structured self-monitoring of blood glucose approach in type 2 diabetes encourages more frequent, intensive, and effective physician interventions: results from the STeP study. Diabetes Technol Ther. 2011;13(8):797-802.

40. Rodbard HW, Schnell O, Unger J, et al. Use of an automated decision support tool optimizes clinicians ability to interpret and appropriately respond to structured self-monitoring of blood glucose data. Diabetes Care. 2012 Feb 16 [Epub ahead of print].

41. Jones TW, Porter P, Sherwin RS, et al. Decreased epinephrine responses to hypoglycemia during sleep. N Engl J Med. 1998;338(23): 1657-1662.

42. Kubiak T, Hermanns N, Schreckling HJ, Kulzer B, Haak T. Evaluation of a self-management-based patient education program for the treatment and prevention of hypoglycemia-related problems in type 1 diabetes. Patient Educ Couns. 2006;60(2):228-234.

43. Strange P. Treat-to-target insulin titration algorithms when initiating long or intermediate acting insulin in type 2 diabetes. J Diabetes Sci Technol. 2007;1(4):540-548.

44. Brunton S. Safety and effectiveness of modern insulin therapy: the value of insulin analogs. Consultant. 2009;Suppl:S13-S19.

45. Clore JN, Thurby-Hay L. Basal insulin therapy. Curr Diab Rep. 2004;4(5):342-345

46. Arnolds S, Kuglin B, Kapitza C, Heise T. How pharmacokinetic and pharmacodynamic principles pave the way for optimal basal insulin therapy in type 2 diabetes. Int J Clin Pract. 2010;64(10): 1415-1434.

47. Heise T, Nosek L, Ronn BB, et al. Lower within-subject variability of insulin detemir in comparison to NPH insulin and insulin glargine in people with type 1 diabetes. Diabetes. 2004;53(6):1614-1620.

48. Valentine WJ, Jendle J, Saraheimo M, Thorsteinsson B, Pollock RF, Lammert M. Evaluating the cost-effectiveness of reduced mild hypoglycaemia in subjects with type 1 diabetes treated with Insulin detemir or NPH insulin in Denmark, Sweden, Finland and the Netherlands. Diabet Med. September 27, 2011. [Epub ahead of print.]

49. Birkeland KI, Home PD, Wendisch U, et al. Insulin degludec in type 1 diabetes: a randomized controlled trial of a new-generation ultra-long-acting insulin compared with insulin glargine. Diabetes Care. 2011;34(3):661-665.

50. Heise T, Hovelmann U, Nosek L, Bottcher SG, Granhall C, Haahr H. Insulin degludec: two-fold longer half-life and more consistent pharmacokinetic profile than insulin glargine. Diabetologia. 2011; 54 Suppl 1:S425.

51. Kurtzhals P, Heise T, Strauss HM, et al. Multi-hexamer formation is the underlying mechanism behind the ultra-long glucose-lowering effect of insulin degludec [Abstract]. Diabetes. 2011;60 Suppl 1A:LB12.

52. Heller S, Francisco AM, Pei H, Russell-Jones D. Insulin degludec improves long-term glycemic control with less nocturnal hypoglycemia compared with insulin glargine: 1-year results from a randomized basal-bolus trial in type 1 diabetes [Abstract]. Diabetes. 2011;60 Suppl 1:A19.

53. Garber AJ, King AB, Francisco A, Endahl LA, Hollander PA. Insulin degludec improves long-term glycemic control with less nocturnal hypoglycemia compared with insulin glargine: 1-year results from a randomized basal-bolus trial in people with type 2 diabetes [Abstract]. Diabetes. 2011;60 Suppl 1:A20. 
54. Meneghini L, Atkin S, Bain S, et al. Flexible once-daily dosing of insulin degludec does not compromise glycemic control or safety compared to insulin glargine given once daily at the same time each day in people with type 2 diabetes [Abstract]. Diabetes. 2011; 60 Suppl 1A:LB10-LB11.

55. Siebenhofer A, Plank J, Berghold A, et al. Short acting insulin analogues versus regular human insulin in patients with diabetes mellitus. Cochrane Database Syst Rev. 2006;2:CD003287.

56. Home PD, Lindholm A, Riis A. Insulin aspart versus. human insulin in the management of long-term blood glucose control in type 1 diabetes mellitus: a randomized controlled trial. Diabet Med. 2000;17(11): 762-770.

57. Heller SR, Amiel SA, Mansell P. Effect of the fast-acting insulin analog lispro on the risk of nocturnal hypoglycemia during intensified insulin therapy. UK Lispro Study Group. Diabetes Care. 1999;22(10): 1607-1611.

58. Yamada S. Insulin glulisine in the management of diabetes. Diabetes Metab Syndr Obes. 2009;2:111-115.

59. Heinemann L, Weyer C, Rauhaus M, Heinrichs S, Heise T. Variability of the metabolic effect of soluble insulin and the rapid-acting insulin analog insulin aspart. Diabetes Care. 1998;21(11):1910-1914.

60. Boehm BO, Home PD, Behrend C, Kamp NM, Lindholm A. Premixed insulin aspart 30 versus. premixed human insulin 30/70 twice daily: a randomized trial in type 1 and type 2 diabetic patients. Diabet Med. 2002;19(5):393-399.

61. Boehm BO, Vaz JA, Brondsted L, Home PD. Long-term efficacy and safety of biphasic insulin aspart in patients with type 2 diabetes. Eur J Intern Med. 2004;15(8):496-502.

62. McNally PG, Dean JD, Morris AD, Wilkinson PD, Compion G, Heller SR. Using continuous glucose monitoring to measure the frequency of low glucose values when using biphasic insulin aspart 30 compared with biphasic human insulin 30: a double-blind crossover study in individuals with type 2 diabetes. Diabetes Care. 2007;30(5):1044-1048.

63. Heise T, Tack CJ, Cuddihy R, et al. A new-generation ultra-long-acting basal insulin with a bolus boost compared with insulin glargine in insulin-naïve people with type 2 diabetes: a randomized, controlled trial. Diabetes Care. 2011;34(3):669-674.

64. Davis SN, Horton ES, Battelino T, Rubin RR, Schulman KA, Tamborlane WV. STAR 3 randomized controlled trial to compare sensor-augmented insulin pump therapy with multiple daily injections in the treatment of type 1 diabetes: research design, methods, and baseline characteristics of enrolled subjects. Diabetes Technol Ther. 2010;12(4):249-255.
65. Bergenstal RM, Tamborlane WV, Ahmann A, et al. Sensor-augmented pump therapy for A1C reduction (STAR 3) study: results from the 6-month continuation phase. Diabetes Care. 2011;34(11):2403-2405.

66. Choudhary P, Shin J, Wang Y, et al. Insulin pump therapy with automated insulin suspension in response to hypoglycemia: reduction in nocturnal hypoglycemia in those at greatest risk. Diabetes Care. 2011;34(9):2023-2025.

67. Pearson TL. Practical aspects of insulin pen devices. J Diabetes Sci Technol. 2010;4(3):522-531.

68. Lee WC, Balu S, Cobden D, Joshi AV, Pashos CL. Medication adherence and the associated health-economic impact among patients with type 2 diabetes mellitus converting to insulin pen therapy: an analysis of third-party managed care claims data. Clin Ther. 2006;28(10): 1712-1725.

69. Spiller HA, Borys DJ, Ryan ML, Sawyer TS, Wilson BL. Unintentional therapeutic errors involving insulin in the ambulatory setting reported to poison centers. Ann Pharmacother. 2011;45(1):17-22.

70. Pfutzner A. FlexPen for the delivery of insulin: accuracy, injection force and patient preference. Expert Rev Med Devices. 2009;6(2):115-123.

71. Campbell RK. Clarifying the role of incretin-based therapies in the treatment of type 2 diabetes mellitus. Clin Ther. 2011;33(5):511-527.

72. Buse JB, Bergenstal RM, Glass LC, et al. Use of twice-daily exenatide in basal insulin-treated patients with type 2 diabetes: a randomized, controlled trial. Ann Intern Med. 2011;154(2):103-112.

73. Yoon NM, Cavaghan MK, Brunelle RL, Roach P. Exenatide added to insulin therapy: a retrospective review of clinical practice over two years in an academic endocrinology outpatient setting. Clin Ther. 2009;31(7):1511-1523.

74. Unger J, Nadeau DA. Defining the role of incretin mimetic therapy in the management of type 2 diabetes. J Fam Pract. 2007; 56(Suppl 12):S4-S10.

75. Cobden D, Lee WC, Balu S, et al. Health outcomes and economic impact of therapy conversion to a biphasic insulin analog pen among privately insured patients with type 2 diabetes mellitus. Pharmacotherapy. 2007;27(7):948-962.

76. Misurski D, Lage MJ, Fabunmi R, et al. A comparison of costs among patients with type 2 diabetes who initiated therapy with exenatide or insulin glargine. Appl Health Econ Health Policy. 2009;7(4):245-254.

\section{Publish your work in this journal}

Diabetes, Metabolic Syndrome and Obesity: Targets and Therapy is an international, peer-reviewed open-access journal committed to the rapid publication of the latest laboratory and clinical findings in the fields of diabetes, metabolic syndrome and obesity research. Original research, review, case reports, hypothesis formation, expert opinion and commentaries are all considered for publication. The manuscript management system is completely online and includes a very quick and fair peer-review system, which is all easy to use. Visit http://www.dovepress.com/testimonials.php to read real quotes from published authors. 